\title{
Teaching Corner: A new method of measuring mid upper arm circumference at Queen Elizabeth Central hospital, Blantyre, Malawi.
}

\section{G. Pollach, S. Mndolo}

Department of Anaesthesia, Queen Elizabeth Central Hospital, Blantyre

\section{Introduction}

Pediatric anesthesia faces many challenges in Africa. Lack of personnel, equipment and late presentation are some of them.

In Malawi malnutrition is another challenge. One in five children is underweight in Malawi. It is therefore necessary for the anaesthetist practising in the Malawian setting to be aware of the effects of malnutrition on their practice.

\section{Why is malnutrition an issue in anaesthesia?}

There is plentiful evidence of adverse effects that malnutrition has on different organs that are of special concern to the anaesthetist. The effects of specific nutritional deficiencies of vitamins and trace elements on the heart are important, although not fully understood. Thiamine deficiency produces peripheral vasodilatation ${ }^{1}$ with resultant high-output cardiac failure, and certain electrolyte deficiencies reduce cardiac contractility ${ }^{1}$. Selenium deficiency has been associated with a cardiomyopathy common in certain regions of $\mathrm{China}^{2}$ and fatal selenium cardiomyopathy has been reported in patients receiving long-term parenteral nutrition. Okoshi and colleagues $^{3}$ demonstrated mechanical, biochemical, and morphological changes in the heart in chronic foodrestricted rats. Fioretto ${ }^{4}$ also noted myocardial dysfunction in rats submitted to protein-calorie malnutrition.

Malnutrition also affects the respiratory system adversely. Rochester and Esau ${ }^{5}$ noted that malnutrition resulted in reduced respiratory drive. It was also noted that malnutrition leads to poor regeneration of respiratory epithelium and that there is high incidence of nosocomial infections among malnourished patients.

Malnutrition also affects the duration of neuromuscular blockade induced by some drugs used during anaesthesia. Nazi et al described prolonged neuromuscular blockade as a result of malnutrition-induced pseudo cholinesterase deficiency ${ }^{6 .}$.

Malnutrition also affects wound healing adversely. Graham and colleagues noted adverse effects of dietary protein deprivation on the healing of colonic anastomosis in rats. ${ }^{7}$

By identifying malnutrion before elective surgery we believe we will be able to avoid the potential problems that can arise as a result of the above pathologies.

There are many methods for assessing the nutritional status including weight for height, height for age and the mid upper arm circumference. The MUAC is more convenient for the anaesthetist because it can be used even with a very sick child who cannot stand. The WHO Standing Committee on Nutrition gives $11 \mathrm{~cm}$ as the cut-off point for severe acute malnutrion. As anaesthetists we want to identify the severely malnourished child. The problem is that the WHO tape measure for measuring MUAC is not always available when you need it!

\section{Objective of study}

The objective of this study was to suggest a method of measuring MUAC which:

- $\quad$ Is almost always available
- $\quad$ Cannot get lost
- $\quad$ Is easy to learn and use
- $\quad$ Cannot be locked up
- $\quad$ Costs nothing

\section{Methodology}

We designed 4 artificial arms with different circumferences using gauze bandages. One had a circumference of $11 \mathrm{~cm}$ and was used as the reference artificial arm.

The others were 9, 10, and $13 \mathrm{~cm}$ respectively. We identified 182 participants; these were health professionals, clinical medical students, preclinical medical students and people from the streets of Blantyre.

Consent to take part was sought verbally. To those that consented to take part an explanation and demonstration of how to use fingers around a reference artificial arm (11CM) to estimate its circumference was given for about five minutes. It was up to their choice which fingers they used. We suggested the use of interphalangeal crests and finger nails.

The reference artificial arm was presented and they were asked to put their fingers around as it was demonstrated.

Then a series of artificial arms were presented at random (including one with the same circumference as the reference arm). Participants were required to judge whether each of the reference arms was smaller than, equal to, or greater than the original.

\section{Results}

Responses were graded as:

- Correct : respondents compared the test arm to the $11 \mathrm{~cm}$ reference arm correctly.

- Acceptable: respondents made a decision that would not have deprived a child from treatment.

- Wrong.

Results 1: overall single decisions

\begin{tabular}{|l|l|}
\hline Decision & $\begin{array}{l}\text { Percentage score out of 728 } \\
\text { possible single decisions (4 x } 182 \\
\text { respondents) }\end{array}$ \\
\hline Correct decisions & 665 of $728(91.3 \%)$. \\
\hline Acceptable decisions & 708 of $728(97.2 \%)$. \\
\hline Wrong decisions & 20 of $728(2.7 \%)$. \\
\hline
\end{tabular}


Results 2: combined decisions.

164 out of 182 respondents (90.1\%) identified the severely malnourished child.

Definition: A single decision on the four sizes that would have excluded the child from treatment would have been judged as 'as not having identified the severely malnourished child'.

Results 2: score for each group

\begin{tabular}{|l|l|}
\hline Group & $\begin{array}{l}\% \text { that identified the severely } \\
\text { malnourished child }\end{array}$ \\
\hline $\begin{array}{l}\text { Anaesthetic clinical officers and } \\
\text { trainee anaesthetic clinical } \\
\text { officers }\end{array}$ & 33 of $36(91.7 \%)$ \\
\hline Clinical medical students & 37 of $39(94.8 \%)$ \\
\hline Preclinical med students & 69 of $76(90.8 \%)$ \\
\hline General public & 25 of $31(80.6 \%)$ \\
\hline
\end{tabular}

Results 3: overall results for the $13 \mathrm{~cm}$

All the 182 respondents were able to identify the normal child (13cm arm circumference).

\section{Discussion}

We have demonstrated that it is possible to measure MUAC using this easy method. We showed that this method is suitable to alert the Malawian anaesthetist for the problems involved in the anaesthetic treatment of severely malnourished children (no elective surgery, referral to NRU, precautions in emergency surgery). We were able to get results comparable to those obtained by Velzeboer and Bradley who used a quantitative method with much more training ${ }^{8,9}$.

Our "tool" is cheap, sustainable, requires minimal training and no maintenance. Differences in experience may explain differences in the accuracy of scores i.e. those who have worked in hospital for some time scored better than their colleagues with minimal experience. The fact that preclinical medical students and members of the general public scored well after minimal training is possibly a suggestion that almost anybody can use this semi-quantitative method.

The fact that everybody $(100 \%)$ recognized the "well fed" child with a $13 \mathrm{~cm}$ MUAC shows that we would not waste resources by referring the wrong children.

\section{Recommendations}

- To train anaesthetic clinical officers to use the method.

\section{We further recommend to:}

- Train community workers (Health Surveillance Assistants) to use our method.

- Train mothers in the villages.

\section{Limitations}

- We used a relatively small group of participants.

- Texture of the real arm is different from that of the artificial arm.

- The participants had very minimal training for only 5 to 10 minutes.

\section{References}

1. Webb, J.G., Kiess, M.C, and Chan-Yan, malnutrition and the heart. Cmaj, 1986.135(7):p.753-8.

2. Frustaci, A., Pennestri and Scoppetta, C, Myocardial damage due to hypokalaemia and hyphosphatamaemia. Postgrad Med J, 1984.60(708):p 679-81

3. Sciences, K.D observations on the effect of sodium selenite in the prevention of keshan disease. Chin Med J, 1979.92:p471-76

4. Fleming CR., Selenium deficiency and fatal cardiomyopathy in a patient on home parenteral nutrition. Gastroentorology, 1982.83(3):p68993.

5. Rochester DF, Esau SA: Malnutrition and the respiratory system; 1984 Mar; 85(3):411-5.

6. Niazi A, Leonard IE, O'Kelly B: Prolonged neuromuscular blockade as a result of malnutrition induced pseudo cholinesterase deficiency: - Journal of Clinical Anesthesia, volume 16 issue 1, Pages 40-42 (February 2004) 2004.

7. Graham L, David A: Journal of Parenteral and Enteral Nutrition 10:550-554, 1986)

8. Velzeboer MI, Selwyn BJ, Sargent F 2nd, Pollitt E, and Delgado $\mathrm{H}$ : The use of arm circumference in simplified screening for acute malnutrition by minimally trained health workers. J Trop Pediatr, 1983, Jun: 29 (3):159; 66

9. Bradley JL, Brown JE, and Himes JH: Reliability and validity of parental measurements of infant size, Am J Hum Biol. 2001 Mar-Apr; 13(2):275-9 